\title{
UV Blocking Glass: Low Cost Filters for Visible Light Photocatalytic Assessment
}

\author{
Charles W. Dunnill \\ Energy Safety Research Institute (ESRI), Swansea University Bay Campus, Fabian Way, SA1 8EN Swansea, UK \\ Correspondence should be addressed to Charles W. Dunnill; c.dunnill@swansea.ac.uk
}

Received 7 October 2014; Accepted 26 November 2014; Published 8 December 2014

Academic Editor: Vincenzo Augugliaro

Copyright ( 2014 Charles W. Dunnill. This is an open access article distributed under the Creative Commons Attribution License, which permits unrestricted use, distribution, and reproduction in any medium, provided the original work is properly cited.

\begin{abstract}
A number of commercially available art protection products have been compared and assessed for their suitability as UV blocking filters in the application of "visible light" photocatalytic research. Many groups claiming visible light photocatalytic success employ filters to block out stray UV radiation in order to justify that their photocatalysts are indeed visible light photocatalysts and not UV light photocatalysts. These filters come in varying degrees of ability and price and many authors fail to correctly characterise their filters in individual papers. The use of effective filters to prevent both false positive and false negative results is important to maintain scientific rigor and create accurate understanding of the subject. The optimum UV filter would have the highest UV blocking properties $(<390 \mathrm{~nm})$ and simultaneously the highest visible light transmission $(390-750 \mathrm{~nm})$. Single and double layers of each of the glass products were assessed as well as laminate products. The conclusions show an inexpensive and highly effective setup for the conduction of visible light photochemistry that should be incorporated as a standard part in any researcher's work where the claim of visible light activity is made.
\end{abstract}

\section{Introduction}

With current advances in visible light photocatalysis taking an increasing limelight in scientific publications there is an escalating importance in the need to accurately prove the presence of "visible light" induced photocatalysis as opposed to photocatalysis that occurs as a result of stray photons of high energy from a visible light source. It is well understood that visible light sources often have stray high energy photons $[1,2]$. In fact it has been observed that the visible light sources often get better with age. They especially improve in effectiveness when dropped (without breaking) or handled roughly. This was explained by virtue of the fact that use and time lead to the delamination of the phosphor coating on the inside of the bulb and the inefficient conversion of high energy emitted radiation into visible wavelength light. Delamination of the phosphor leaves holes through which the UV light can escape. This leaking UV light can lead to false positive claims of visible light photocatalysts [1]. A visible light photocatalyst should operate under visible light with only the visible spectrum, that is, $390 \mathrm{~nm}$ to $750 \mathrm{~nm}$. Leakage of $>750 \mathrm{~nm}$ light is not an issue for obvious reasons; however leakage of even a tiny amount of $<390 \mathrm{~nm}$ light would lead to false positive recordings [2].

The solution is to employ a UV light blocking filter that sits between the light source and the sample filtering out all the high energy radiation $<390 \mathrm{~nm}$. There are however a number of different filters currently on the market with different prices and UV blocking abilities. UV filters are readily available as a result of the desire to protect valuable art work from the damage caused by UV radiation with many options procurable off the shelf. Within the research area there is however a need for reliable filters that are known to be effective and hence add reproducibility and scientific rigor to the results and conclusions. Many authors do use pass filters with specific cutoff bands [3-9] at 400 or $420 \mathrm{~nm}$ or art work protection screens such as Optivex $[10,11]$, though in many cases there is little or no published comment on their actual ability to perform and reduce the risk of false positive publication of "visible light" photocatalysts. Some modern photocatalysis is so effective under UV light that even a small fraction of a percent leakage can be seen to have a significant effect. 
In this paper a number of different art protection product glass filters are compared specifically for their advantages and disadvantages in their use as UV filters for the application of visible light photocatalytic assessment, using UV-Vis spectroscopy. The conclusions show an inexpensive and highly effective UV blocking filter that can and should be incorporated into the experimental setup for the conduction of visible light photochemistry experiments. Such experiments cover a wide range of application bases, not limited to solar energy harvesting $[3,12]$, self-cleaning surfaces [13-15], and antimicrobial applications [16-18].

\section{Methods}

Six different glass samples were placed in a Perkin Elmer $\lambda 950 \mathrm{UV}-\mathrm{Vis}$ spectrometer and the spectrum was acquired from 800 to $200 \mathrm{~nm}$ with a $1 \mathrm{~nm}$ resolution. The results were graphically compared to one and others with data collected both for an individual and for a double layer of each sample. The samples were Museum Glass, Art Glass, Conservation Glass, and Optivex. Two different laminate glasses were also considered; these were Art Glass Laminate and True View Laminate. The laminate glasses are designed to give added protection both in UV blocking and physical security to valuable pieces of art. Samples were assessed as to their function at blocking the UV and for their transmission within the visible range of wavelengths 390-750 nm.

The Museum Glass [19], Glass [20], Conservation Glass [21], True View Laminate [19], and Art Glass Laminate [20] samples were supplied by the London branch of Wessex Pictures and the Optivex was purchased from Instrument Glasses Ltd. All samples were used as supplied and contain UV blocking coatings as well as antireflective coatings.

\section{Results and Discussion}

For the sake of discussion a theoretical perfect behaving model was invented. In this model we see $100 \%$ blocking of the UV spectrum below $390 \mathrm{~nm}$ and $100 \%$ transmission above. Although unrealistic in expectation for a UV filter to behave in this way it is at least a guide as to what the optimum filter would behave like and allows us to statistically compare the different samples with respect to this model. This model has been added to the plots as the hypothetical scenario.

The UV-visible spectrum for the single thickness and double thickness of each of the samples is shown in Figure 1, alongside the hypothetical optimised trace. All data is displayed between 200 and $800 \mathrm{~nm}$ and the 1 or 2 indicates the number of sheets of glass that were included.

The results clearly show that there is a large difference between the different samples with some displaying visible colour alterations within their spectrums. The Museum Glass and Conservation Glass both claim a 98\% reduction in UV with single sheets performing well due to their silicone coatings. The downside here is that both have a fairly significant tail in the UV section and a relatively low transmission in the visible. Conservation Glass especially shows both of these traits. In order to cut out the tail a second layer would be required; however this then further reduces the transmission in the visible range. While the Museum Glass is more transmitting than the conservation Glass, the unevenness in both the spectrums leads to a clear red tint in both cases. The Art Glass is on an iron free crystal substrate so it has a 99\% (manufacturer claim) transmission in the visible range; however it does only carry a 92\% UV absorption claim compared to the $98 \%$ of the Museum Glass and Conservation Glass. The Optivex achieves a total blocking of UV below the $390 \mathrm{~nm}$ cutoff; however much of the potentially useful purple visible light is blocked off as well, possibly resulting in false negative results for visible light photocatalysis. There is no apparent advantage for having a second layer of Optivex over a single layer as the reduction in UV transmission is outweighed by the loss in transmission of the visible light so the single layer has been considered to be better.

The True View Laminate is a laminated sheet of Museum Glass with the same antireflective coating on both sides; however it has a UV absorbing adhesive between the sheets that cuts out $99 \%$ of the UV whilst retaining the high transmission in the visible range as does the Art Glass Laminate which is a similar product made using two sheets of Art Glass.

3.1. Integration of UV-Vis Data. The UV-Vis data was quantified using the numeric integration of the lines utilising trapezium rule at $1 \mathrm{~nm}$ resolution. The sum of all the trapezia above and below the $390 \mathrm{~nm}$ cutoff was taken and normalised against the areas calculated for the hypothetical spectra to give a \% UV absorption and \% visible transmission. Based on a $100 \%$ transmission from 200 to $390 \mathrm{~nm}$ it is possible to record an integrated area of 18950 units; hence \% UV absorption was calculated as the area present against this value.

As visible light photocatalyst is in general operating with the most energetic photons that are available it is not really a fair assessment to equally weight all visible light photons. A photon on the red region up at $800 \mathrm{~nm}$ will likely have a smaller effect on a visible light photocatalyst than one down in the $400 \mathrm{~nm}$ region. To take this into account the integrations were repeated splitting the visible region into three equal sections. These ranges considered are $390-527 \mathrm{~nm}, 527-663 \mathrm{~nm}$, and $663-800 \mathrm{~nm}$. Table 2 shows the $\%$ transmission based on $100 \%$ transmission in each of the regions. It is in this table that the best performing filters from Table 1 begin to show some differences. Optivex which was the best UV blocking glass now shows a lower transmission in the upper region when compared to the double layers of Museum Glass and True View Laminate. The single layer of Optivex has 73\% transmission of this high end visible light, compared to 81 and $82 \%$, respectively. It is possible to conclude here that true visible light photocatalysts will perform better in testing under the same light source should the Museum Glass or True View Laminate be used as filters.

3.2. Cost Analysis. The cost of the glass is obviously important criteria and simple quotes for an A4 sheet sized filter were obtained. The prices will obviously vary from different retailers; however when sourced, the glass in single sheets of Art 

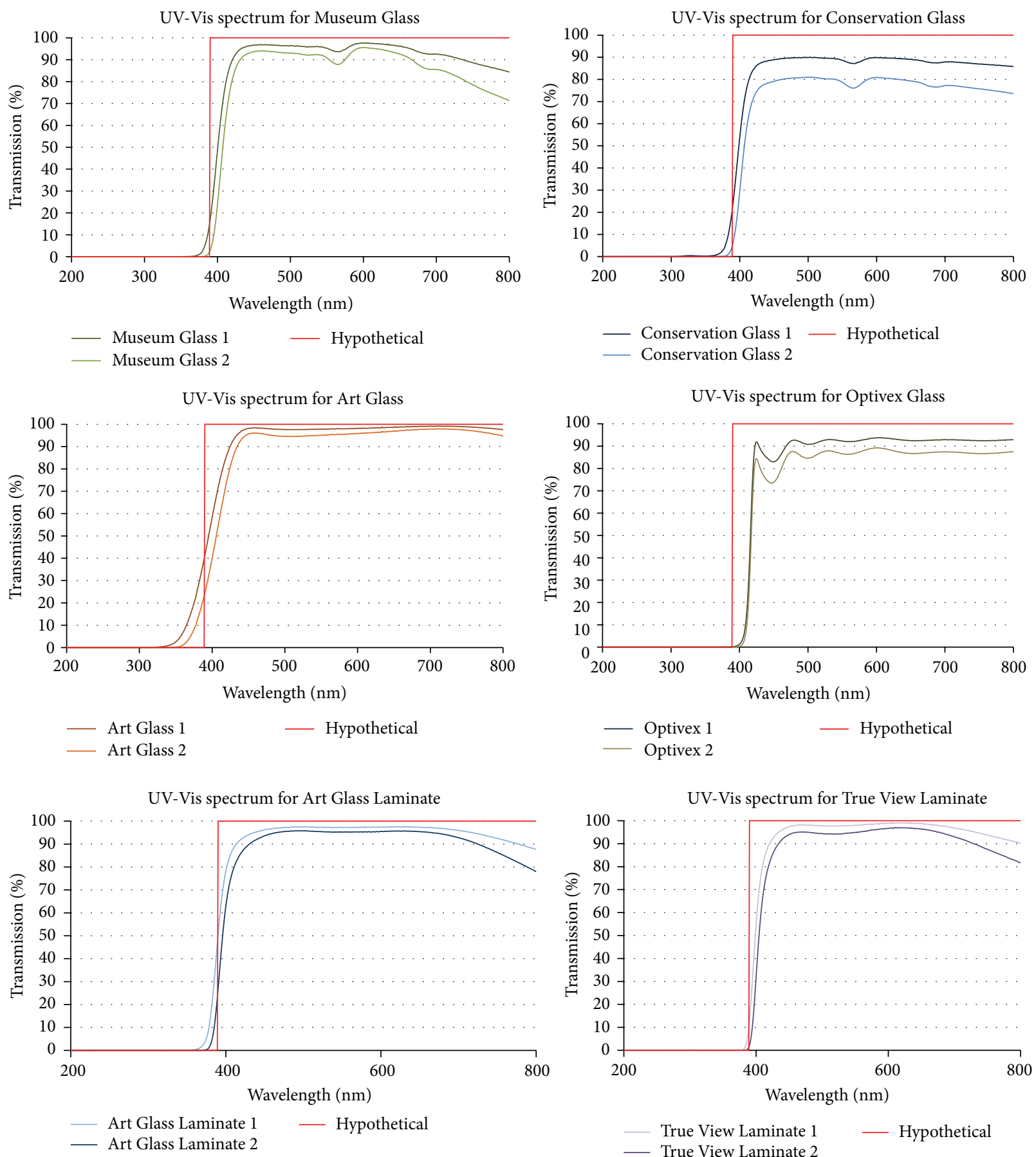

Figure 1: Data for the \% transmission for each of the samples plotted against the hypothetical ideal plot; the number in the sample names indicates the number of sheets of the sample glass that were used.

Glass, Museum Glass, and Conservation Glass were $<£ 10$, the True View Laminate was $<£ 20$, and the Optivex was $>£ 300$ for an A4 sized sheet. This has serious implications with the use of a double layer of Optivex.

\section{Conclusions}

Four of the setups above would potentially be suitable as UV blocking filters for conducting visible light photocatalytic reactions. The best functioning UV blocking filter from the samples above is the double layer of True View Laminate Glass. True View Laminate was found to be $99.995 \%$ UV blocking whilst retaining $90 \%$ of the visible transmission, with the highest transmission at the more energetic side of the visible spectrum and with a reasonable price tag. The use of True View Laminate Glass as a double sheet is highly recommended for the best performance and cost advantages, $\sim £ 40$ per A4 sheet setup. 
TABLE 1: The integrated area of the transmission below and above the $390 \mathrm{~nm}$ cutoff. The best 4 performing samples are highlighted in bold $>99.95 \%$ UV blocking.

\begin{tabular}{lcccc}
\hline Sample name & Integration below $390 \mathrm{~nm}$ & \% UV absorption & Integration 390-800 nm & \% visible transmission \\
\hline Hypothetical & 0 & 100.00 & 41050 & 37478 \\
Museum Glass 1 & 83 & 99.56 & $\mathbf{3 4 8 0 8}$ & 91.30 \\
Museum Glass 2 & $\mathbf{6}$ & $\mathbf{9 9 . 9 7}$ & 35456 & $\mathbf{8 4 . 7 9}$ \\
Conservation Glass 1 & 161 & 99.15 & 30979 & 86.37 \\
Conservation Glass 2 & 17 & 99.91 & 39262 & 75.47 \\
Art Glass 1 & 666 & 96.49 & 37919 & 95.64 \\
Art Glass 2 & 273 & 98.56 & $\mathbf{3 5 3 7 4}$ & $\mathbf{9 2 . 3 7}$ \\
Optivex 1 & $\mathbf{1}$ & $\mathbf{9 9 . 9 9}$ & $\mathbf{3 3 0 4 5}$ & $\mathbf{8 6 . 1 7}$ \\
Optivex 2 & $\mathbf{0}$ & $\mathbf{1 0 0 . 0 0}$ & 38668 & $\mathbf{8 0 . 5 0}$ \\
True View Laminate 1 & 30 & 99.84 & $\mathbf{3 6 6 7 3}$ & $\mathbf{9 4 . 2 0}$ \\
True View Laminate 2 & $\mathbf{1}$ & $\mathbf{9 9 . 9 9}$ & 38826 & $\mathbf{8 9 . 3 4}$ \\
Art Glass Laminate 1 & 338 & 98.22 & 37170 & 94.57 \\
Art Glass Laminate 2 & 98 & 99.48 & & 90.55 \\
\hline
\end{tabular}

TABLE 2: The \% integrated area transmission for each of the best performing UV blocking samples in three ranges of wavelength within the visible region of the spectrum.

\begin{tabular}{lccc}
\hline Sample name & $\%$ & $\%$ & $\%$ \\
& $390-527 \mathrm{~nm}$ & $527-663 \mathrm{~nm}$ & $663-800 \mathrm{~nm}$ \\
\hline Hypothetical & 100 & 100 & 100 \\
Museum Glass 2 & 81 & 93 & 81 \\
Optivex 1 & 73 & 93 & 93 \\
Optivex 2 & 67 & 88 & 87 \\
True View Laminate 2 & $\mathbf{8 2}$ & $\mathbf{9 6}$ & $\mathbf{8 9}$ \\
\hline
\end{tabular}

\section{Conflict of Interests}

The author declares that there is no conflict of interests regarding the publication of this paper.

\section{Acknowledgments}

Charles W. Dunnillthanks the Ramsay Trust for his Ramsay fellowship and Wessex Pictures for many of the glass samples. Dunnill also thanks Ivan Parkin at UCL for support and the use of equipment at UCL.

\section{References}

[1] C. W. Dunnill and I. P. Parkin, "Nitrogen-doped $\mathrm{TiO}_{2}$ thin films: photocatalytic applications for healthcare environments," Dalton Transactions, vol. 40, no. 8, pp. 1635-1640, 2011.

[2] C. W. H. Dunnill, Z. A. Aiken, J. Pratten, M. Wilson, D. J. Morgan, and I. P. Parkin, "Enhanced photocatalytic activity under visible light in $\mathrm{N}$-doped $\mathrm{TiO}_{2}$ thin films produced by APCVD preparations using t-butylamine as a nitrogen source and their potential for antibacterial films," Journal of Photochemistry and Photobiology A: Chemistry, vol. 207, no. 2-3, pp. 244-253, 2009.

[3] Z. Zou, J. Ye, K. Sayama, and H. Arakawa, "Direct splitting of water under visible light irradiation with an oxide semiconductor photocatalyst," Nature, vol. 414, no. 6864, pp. 625-627, 2001.
[4] R. Asahi, T. Morikawa, T. Ohwaki, K. Aoki, and Y. Taga, "Visible-light photocatalysis in nitrogen-doped titanium oxides," Science, vol. 293, no. 5528, pp. 269-271, 2001.

[5] M. Shao, J. Han, M. Wei, D. G. Evans, and X. Duan, “The synthesis of hierarchical Zn-Ti layered double hydroxide for efficient visible-light photocatalysis," Chemical Engineering Journal, vol. 168, no. 2, pp. 519-524, 2011.

[6] C.-C. Hu, T.-C. Hsu, and S.-Y. Lu, "Effect of nitrogen doping on the microstructure and visible light photocatalysis of titanate nanotubes by a facile cohydrothermal synthesis via urea treatment," Applied Surface Science, vol. 280, pp. 171-178, 2013.

[7] X. Lin, F. Rong, X. Ji, D. Fu, and C. Yuan, "Preparation and enhanced visible light photocatalytic activity of N-doped Titanate nanotubes by loaded with $\mathrm{Ag}$ for the degradation of X-3B," Solid State Sciences, vol. 13, no. 7, pp. 1424-1428, 2011.

[8] F. Dong, W. Zhao, Z. Wu, and S. Guo, "Band structure and visible light photocatalytic activity of multi-type nitrogen doped $\mathrm{TiO}_{2}$ nanoparticles prepared by thermal decomposition," Journal of Hazardous Materials, vol. 162, no. 2-3, pp. 763-770, 2009.

[9] H. Sun, G. Zhou, S. Liu, H. M. Ang, M. O. Tadé, and S. Wang, "Visible light responsive titania photocatalysts codoped by nitrogen and metal ( $\mathrm{Fe}, \mathrm{Ni}, \mathrm{Ag}$, or $\mathrm{Pt}$ ) for remediation of aqueous pollutants," Chemical Engineering Journal, vol. 231, pp. 18-25, 2013.

[10] C. W. Dunnill, Z. Ansari, A. Kafizas et al., "Visible light photocatalysts- $\mathrm{N}$-doped $\mathrm{TiO}_{2}$ by sol-gel, enhanced with surface bound silver nanoparticle islands," Journal of Materials Chemistry, vol. 21, no. 32, pp. 11854-11861, 2011.

[11] A. Kafizas, C. W. Dunnill, and I. P. Parkin, "The relationship between photocatalytic activity and photochromic state of nanoparticulate silver surface loaded titanium dioxide thinfilms," Physical Chemistry Chemical Physics, vol. 13, no. 30, pp. 13827-13838, 2011.

[12] K. Maeda, K. Teramura, D. Lu et al., "Photocatalyst releasing hydrogen from water," Nature, vol. 440, no. 7082, article 295, 2006.

[13] C. W. Dunnill, Z. A. Aiken, J. Pratten, M. Wilson, and I. P. Parkin, "Sulfur-and nitrogen-doped titania biomaterials via APCVD," Chemical Vapor Deposition, vol. 16, no. 1-3, pp. 50$54,2010$. 
[14] C. W. Dunnill, Z. A. Aiken, A. Kafizas et al., "White light induced photocatalytic activity of sulfur-doped $\mathrm{TiO}_{2}$ thin films and their potential for antibacterial application," Journal of Materials Chemistry, vol. 19, no. 46, pp. 8747-8754, 2009.

[15] C. W. Dunnill, K. Page, Z. A. Aiken et al., "Nanoparticulate silver coated-titania thin films-photo-oxidative destruction of stearic acid under different light sources and antimicrobial effects under hospital lighting conditions," Journal of Photochemistry and Photobiology A: Chemistry, vol. 220, no. 2-3, pp. 113-123, 2011.

[16] S. Noimark, C. W. Dunnill, and I. P. Parkin, "Shining light on materials-a self-sterilising revolution," Advanced Drug Delivery Reviews, vol. 65, no. 4, pp. 570-580, 2013.

[17] S. Noimark, C. W. Dunnill, M. Wilson, and I. P. Parkin, "The role of surfaces in catheter-associated infections," Chemical Society Reviews, vol. 38, no. 12, pp. 3435-3448, 2009.

[18] S. Noimark, C. W. Dunnill, C. W. M. Kay et al., "Incorporation of methylene blue and nanogold into polyvinyl chloride catheters; A new approach for light-activated disinfection of surfaces," Journal of Materials Chemistry, vol. 22, no. 30, pp. 15388-15396, 2012.

[19] Museum Glass, 2013, http://www.wessexpictures.com/museum_glass.html.

[20] "Art Glass," 2013, http://www.wessexpictures.com/artglass .html.

[21] Conservation Glass, 2013, http://www.wessexpictures.com/ conservation_clear.html. 

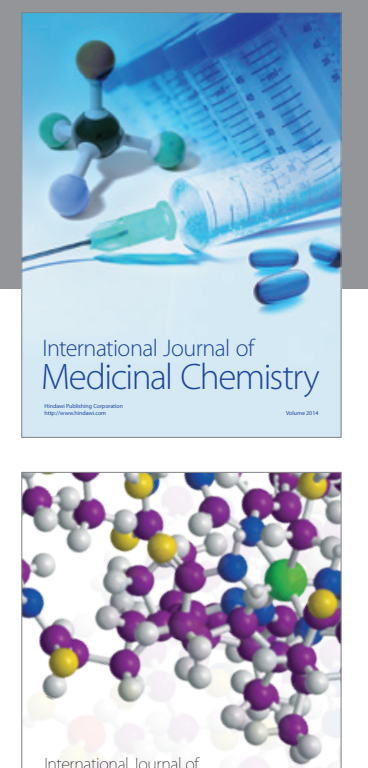

\section{Carbohydrate} Chemistry

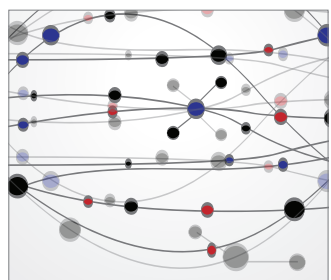

The Scientific World Journal
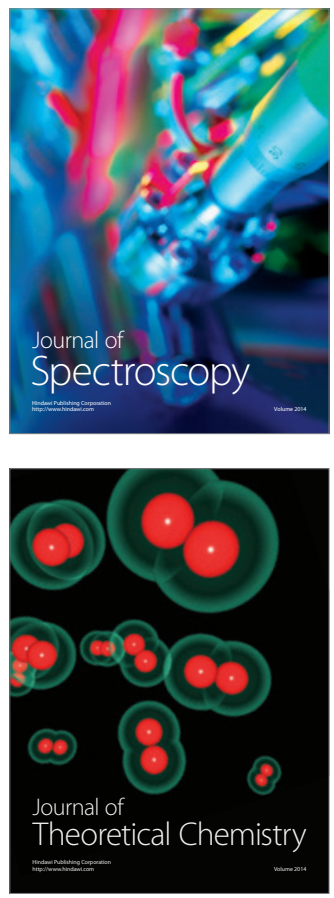
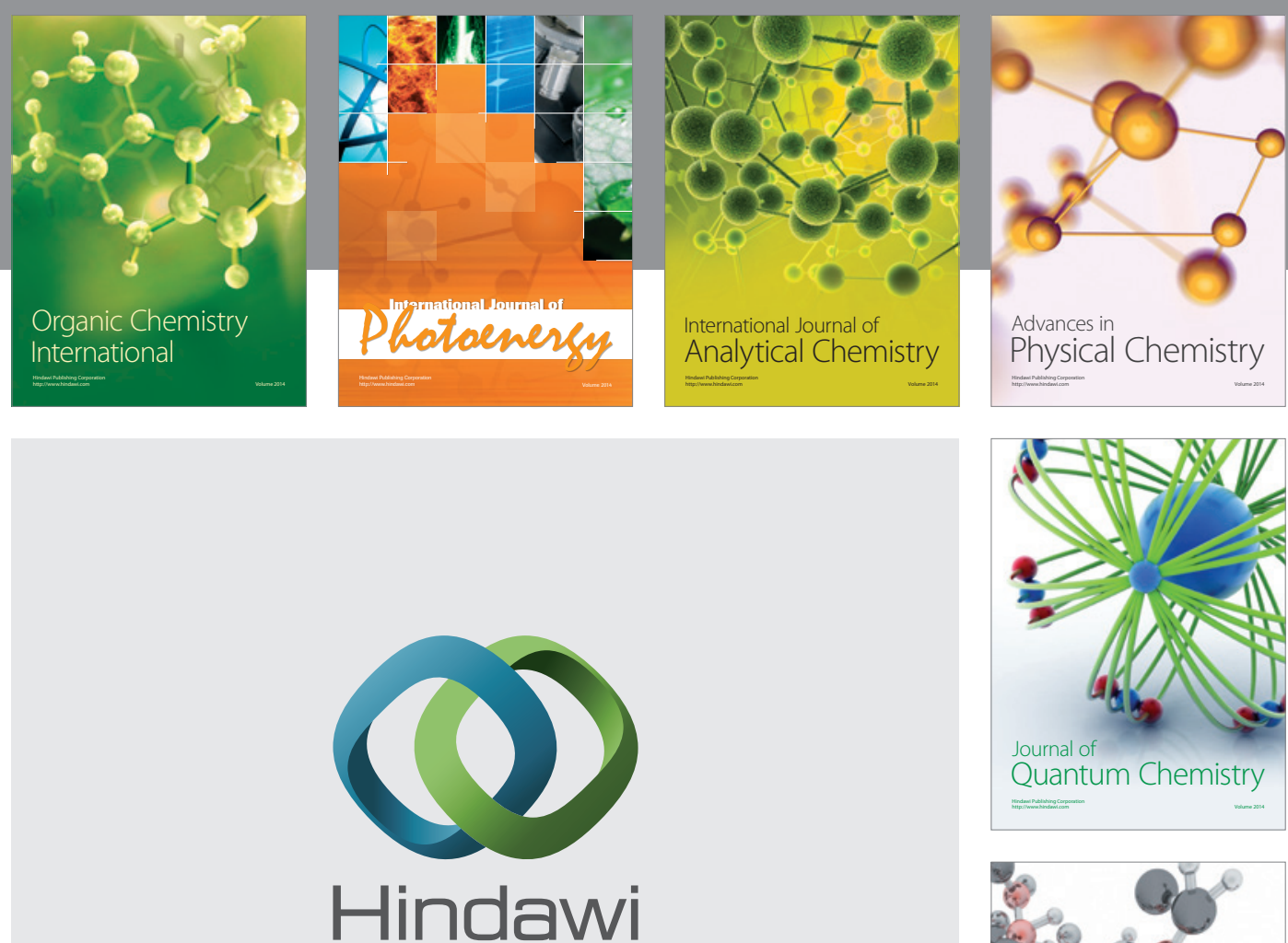

Submit your manuscripts at

http://www.hindawi.com

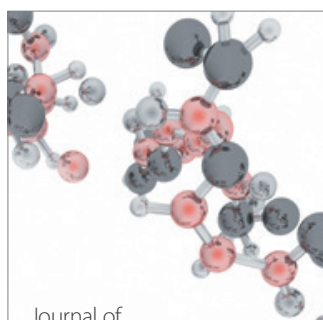

Analytical Methods

in Chemistry

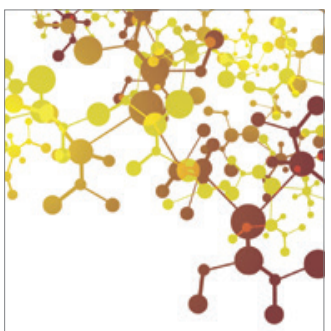

Journal of

Applied Chemistry

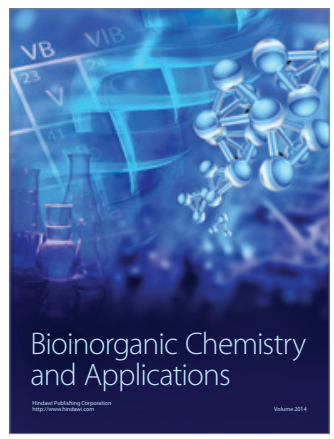

Inorganic Chemistry
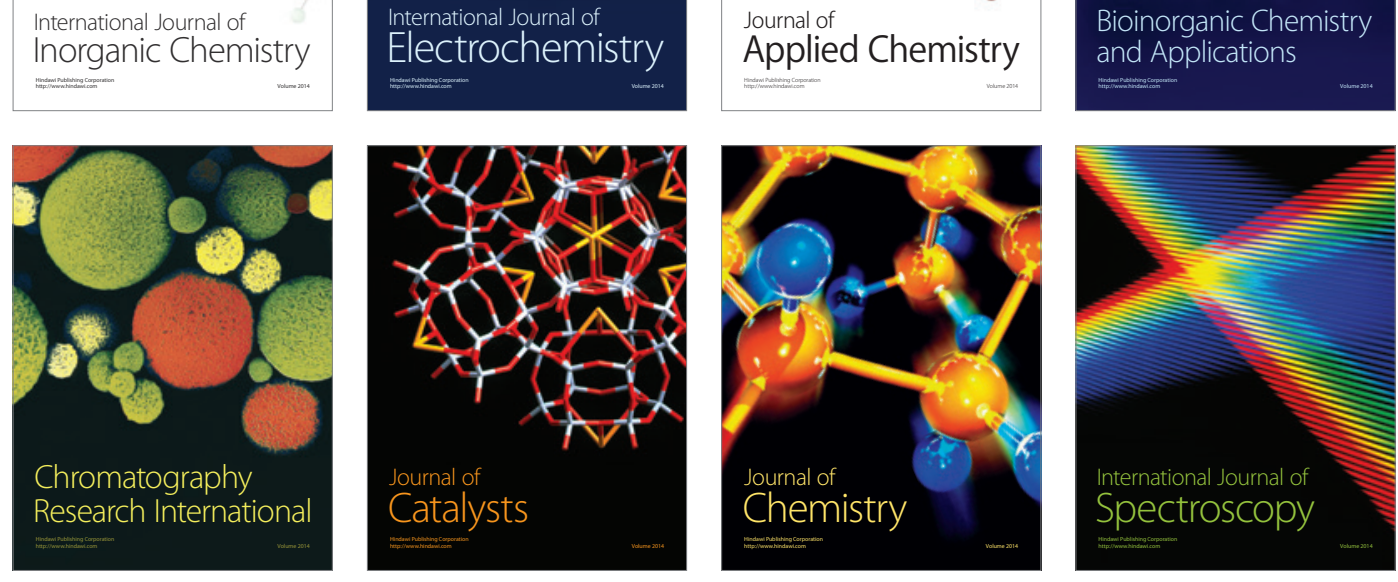